\title{
Hindcasts of Tropical Atlantic SST Gradient and South American Precipitation: The Influences of the ENSO Forcing and the Atlantic Preconditioning
}

\author{
HUEI-PING HUANG \\ Department of Mechanical and Aerospace Engineering, Arizona State University, Tempe, Arizona \\ ANDREW W. ROBERTSON \\ International Research Institute for Climate and Society, Columbia University, New York, New York \\ YOCHANAN KUSHNIR \\ Lamont-Doherty Earth Observatory of Columbia University, Palisades, New York

\section{SHILING PENG} \\ NOAA/Earth System Research Laboratory/Physical Science Division, and CIRES Climate Diagnostics Center, \\ University of Colorado, Boulder, Colorado
}

(Manuscript received 9 April 2008, in final form 1 November 2008)

\begin{abstract}
Hindcast experiments for the tropical Atlantic sea surface temperature (SST) gradient G1, defined as tropical North Atlantic SST anomaly minus tropical South Atlantic SST anomaly, are performed using an atmospheric general circulation model coupled to a mixed layer ocean over the Atlantic to quantify the contributions of the El Niño-Southern Oscillation (ENSO) forcing and the preconditioning in the Atlantic to G1 in boreal spring. The results confirm previous observational analyses that, in the years with a persistent ENSO SST anomaly from boreal winter to spring, the ENSO forcing plays a primary role in determining the tendency of G1 from winter to spring and the sign of G1 in late spring. In the hindcasts, the initial perturbations in Atlantic SST in boreal winter are found to generally persist beyond a season, leaving a secondary but nonnegligible contribution to the predicted Atlantic SST gradient in spring. For 1993/94, a neutral year with a large preexisting G1 in winter, the hindcast using the information of Atlantic preconditioning alone is found to reproduce the observed G1 in spring. The seasonal predictability in precipitation over South America is examined in the hindcast experiments. For the recent events that can be validated with highquality observations, the hindcasts produced dryness in boreal spring 1983, wetness in spring 1996, and wetness in spring 1994 over northern Brazil that are qualitatively consistent with observations. An inclusion of the Atlantic preconditioning is found to help the prediction of South American rainfall in boreal spring. For the ENSO years, discrepancies remain between the hindcast and observed precipitation anomalies over northern and equatorial South America, an error that is partially attributed to the biased atmospheric response to ENSO forcing in the model. The hindcast of the 1993/94 neutral year does not suffer this error. It constitutes an intriguing example of useful seasonal forecast of G1 and South American rainfall anomalies without ENSO.
\end{abstract}

\section{Introduction}

The research in the predictability of tropical Atlantic meridional SST gradient has a long history since early

Corresponding author address: Huei-Ping Huang, Department of Mechanical and Aerospace Engineering, Arizona State University, Tempe, AZ 85287-6106.

E-mail: hp.huang@asu.edu studies suggested its potential influences on the rainfall anomaly over the Nordeste (east-northeastern Brazil) region of South America (e.g., Nobre and Molion 1988; see the survey in Uvo et al. 1998). Using station data for precipitation, previous observational analyses (e.g., Giannini et al. 2004) showed that, in boreal spring, the Nordeste region tends to be drier than normal with a positive Atlantic SST gradient G1 [defined as tropical North Atlantic SST anomaly (tNA) minus tropical 
South Atlantic SST anomaly (tSA)] because a warmer than normal tNA or a colder than normal tSA drives the Atlantic ITCZ northward, away from the Nordeste. (See Fig. 1 and caption for definitions of tNA and tSA boxes.) Conversely, a negative G1 implies wetness over northern Brazil. This suggests the possibility of incorporating the prediction of $\mathrm{G} 1$ in the practical prediction of the rainfall anomalies over South America.

Among the two components of SSTs that define G1, tNA is known to be more strongly influenced by ENSO and is positively correlated with the Niño-3 SST index (e.g., Enfield and Mayer 1997; Alexander and Scott 2002; Huang et al. 2005a), while tSA is recognized as being regulated by local internal variability (e.g., Chang et al. 1998; Czaja et al. 2002; Barreiro et al. 2004, 2005; Trzaska et al. 2007). Thus, G1 tends to have the same sign as the Niño-3 index in the boreal spring of "year 1" (the year that follows the December peak of an El Niño or La Niña) of a strong ENSO event after the influence of ENSO on the Atlantic is fully established. Using the observation from 1876 to 1997, Huang et al. (2005a) clarified that about two-thirds of the strong ENSO events are concordant, in the sense (as envisioned by Giannini et al. 2004) that G1 in boreal spring has the same sign as the Niño-3 index averaged from the preceding winter to early spring. The other one-third are discordant, for which the ENSO forcing from boreal winter to spring is not sufficient to overturn a preexisting Atlantic SST gradient such that G1 and Niño-3 have opposite signs in spring. In the discordant cases, tSA in boreal spring can often be tracked back to a strong preexisting SST anomaly (SSTA) in the central South Atlantic in the preceding boreal winter (Huang et al. 2005a; Barreiro et al. 2004). Figure 1, adapted from Huang et al. (2005a), illustrates the composites of the SST anomalies for the (a) concordant and (b) discordant cases and the (c) typical precondition for the latter. Following previous work (Giannini et al. 2004; Huang et al. 2005a), the two boxes in Fig. 1a are chosen to define the tNA and tSA used in this study. Based on the observational analysis, G1 in boreal spring should generally depend on the ENSO forcing from boreal winter to spring and the preconditioning in the Atlantic SST in boreal winter. In this study, we will use a series of GCM hindcast experiments to assess the contributions of these two components to the seasonal predictability in the Atlantic SST and in the precipitation over South America.

We will analyze the behavior of the simulated SST anomalies in ensemble hindcast experiments using an atmospheric GCM partially coupled to a mixed layer ocean model for the Atlantic. The experimental design is described in section 2. The results of the model sim-
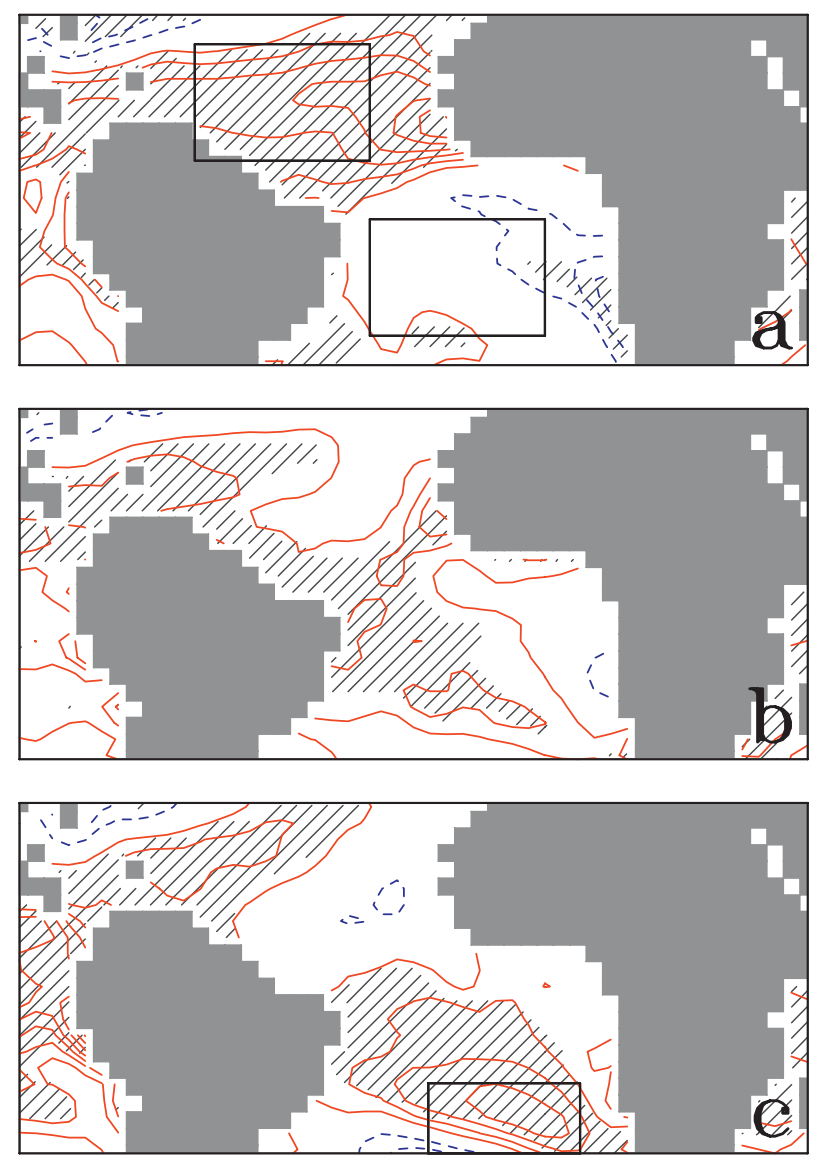

FIG. 1. Composites of the March-May SST anomalies for the (a) concordant and (b) discordant cases for all major ENSO warm events from 1865 to 2000 . A concordant case is defined as one in which the tropical Atlantic SST gradient, G1, in March-May has the same sign as the Niño-3 index in the preceding DecemberJanuary. A discordant case is the opposite. (c) The composite of the SST anomalies in January-March, that is, precursor to the SST anomaly in (b), for the discordant cases. The tNA $\left(5^{\circ}-25^{\circ} \mathrm{N}, 60^{\circ}-\right.$ $\left.30^{\circ} \mathrm{W}\right)$ and tSA $\left(25^{\circ}-5^{\circ} \mathrm{S}, 30^{\circ} \mathrm{W}-0^{\circ}\right)$ boxes are marked in (a). Contour interval is $0.1^{\circ} \mathrm{C}$, negative dashed. Shading indicates a high level $(>95 \%)$ of statistical significance. Adapted from Huang et al. (2005a).

ulations of the Atlantic SST and SST gradient are discussed in section 3. In addition to the SST, the modelpredicted precipitation anomalies will be analyzed in section 4 in the context of the relationships among the Atlantic SST gradient, ENSO forcing, and South American rainfall anomalies. Concluding remarks follow in section 5 .

\section{The model and numerical experiments}

\section{a. Selection of cases}

We will focus on selected years with the combinations of one or more of the following conditions: (i) Persistent 
ENSO forcing from late boreal winter to boreal spring; (ii) a strong preconditioning in the Atlantic SST in boreal winter; (iii) a large tendency or strong persistence in G1 from late boreal winter to boreal spring. These criteria are quantified by the monthly Niño-3 and G1 indices as shown in Fig. 2. They are detrended with a 10-yr high-pass filter in the same manner as in Huang et al. (2005a). (The observed SST anomalies used in the initial condition of our hindcast experiments and those used for model verification are also preprocessed in the same way.) Each grid box represents one month and each row in one of the panels in Fig. 2, from left to right, represents one year, defined as July of one year (called "year 0") to June of the following year (called "year 1"), with time increasing downward from 1947 to 1997 (the top row is July 1947-June 1948; bottom row is July 1996-June 1997.) Note that the color interval, shown at bottom, for G1 is only one-third of that for Niño-3. Visually, the right panel looks noisier than the left panel; the Niño-3 index exhibits a greater degree of month-to-month persistence. However, the persistence of Niño-3 is stronger in the first half (from boreal summer of year 0 to boreal winter of year $0 / 1$ ) of the ENSO year, leaving us a reduced number of cases with the desired condition of a persistent ENSO forcing from boreal winter to spring of year 1, the time of year when G1 is important. Among these cases, a few are found to have a large tendency (large increase or decrease during the season) or strong persistence in G1 from boreal winter to spring. They are selected for our hindcast experiments as marked by the arrows in Fig. 2. They include two ENSO warm events (1968/69 and 1982/83) and three cold events $(1970 / 71,1988 / 89$, and 1995/96). In addition, we selected a neutral year of 1993/94 that is distinguished by a strong preconditioning in winter and strong persistence of G1 from winter to spring. We have chosen the cases from the last 30 years of the twentieth century for which there are more high-quality observational data (for Atlantic SST and precipitation) available to validate the hindcast.

The cases chosen are listed in Table 1 . The majority of the ENSO events in that list are concordant; that is, the G1 index in late boreal spring has the same sign as the Niño-3 index averaged from late boreal winter to boreal spring. In most of them, G1 changes sign from positive in late boreal winter to negative in late boreal spring for ENSO cold events, and from negative to positive for ENSO warm events. This is expected, as we have chosen the cases with strong ENSO in boreal winter-spring. They correspond to (by the ENSO-tNA connection, see section 3) the cases with the largest tendency in G1 from late boreal winter to late boreal spring-thus the likelihood of having G1 changing sign over that period. These
NINO3

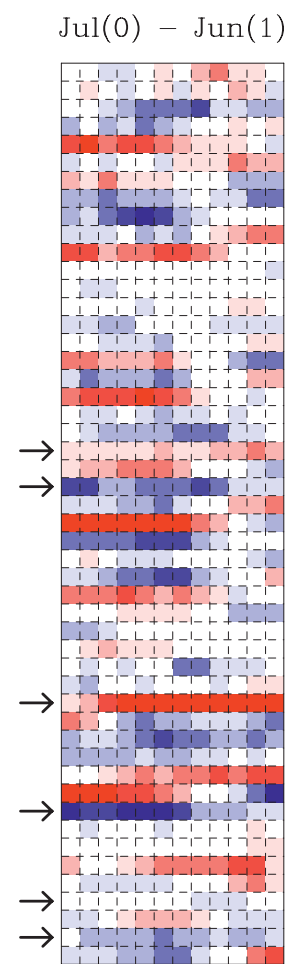

G1

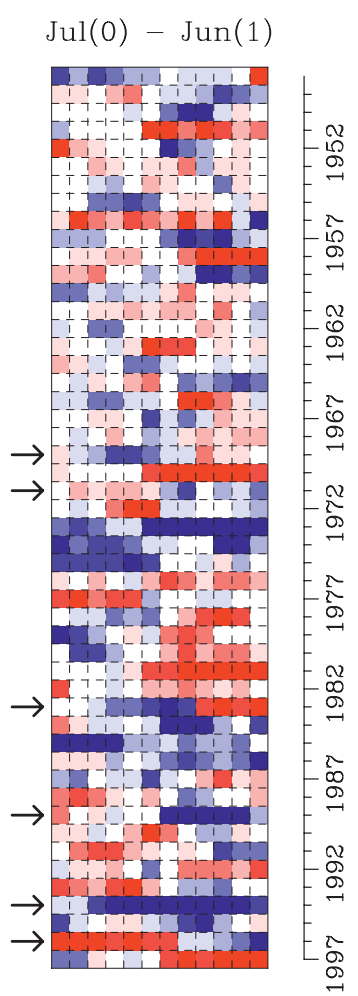

G1

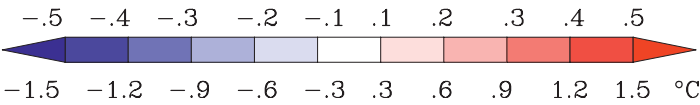

FIG. 2 Observed monthly-mean (right) tropical Atlantic SST index G1 and (left) Niño-3 SST index for 1948-97. Each row is a year, defined as July of year 0 to June of year 1. (top) July $1947-$ June 1948; (bottom) July 1996-June 1997. The years indicated by an arrow are selected for our hindcast experiments. The year indicated at right corresponds to year 1 . The color scales are shown at the bottom. Note that the color interval for G1 is one-third of that for Niño-3.

cases are chosen because the large seasonal tendency in G1 makes it easier to interpret the results of our numerical experiments. The cases with G1 having the same sign through the boreal winter-spring season [which can be either concordant or discordant, the latter is mostly associated with weak ENSO events; see Huang et al. (2005a)] are weak ENSO or neutral events. They are not chosen because, in the observation (to be used to verify the hindcast), the weak seasonal tendency in G1 in these cases is more easily overwhelmed by the subseasonal variability in $\mathrm{G} 1$, rendering it difficult to verify and interpret the ENSO-induced tendency in the hindcast. (See section $2 b$ for the setup of the hindcast experiments.) Otherwise, we have evenly sampled ENSO warm and cold events that are known to exhibit some degree of asymmetry in their remote atmospheric responses (e.g., Sardeshmukh et al. 2000). 
TABLE 1. Summary of the major hindcast runs performed for this study. Each case, indicated by a tick mark, consists of 25 one-yr runs from September of year 0 to August of year 1 and with coupling to the mixed layer model over the Atlantic switched on 1 Nov of year 0. ENSO warm and cold events are indicated at right.

\begin{tabular}{lcccll}
\hline \hline & & & \multicolumn{3}{c}{ No ENSO, } \\
& ENSO-only & ENSO+IC & IC-only & no IC & Remark \\
\hline $1968-89$ & $\sqrt{ }$ & $\sqrt{ }$ & $\sqrt{ }$ & & Warm \\
$1970-71$ & $\sqrt{ }$ & $\sqrt{ }$ & $\sqrt{ }$ & & Cold \\
$1982-83$ & $\sqrt{ }$ & $\sqrt{ }$ & $\sqrt{ }$ & & Warm \\
$1988-89$ & $\sqrt{ }$ & $\sqrt{ }$ & $\sqrt{ }$ & & Cold \\
$1993-94$ & & $\sqrt{ }$ & $\sqrt{ }$ & & Neutral \\
$1995-96$ & $\sqrt{ }$ & $\sqrt{ }$ & $\sqrt{ }$ & & \\
& & & & $\sqrt{ }$ & \\
Control & & & & $\sqrt{ }$
\end{tabular}

\section{b. The model and experimental design}

The hindcast model is a T42 28-level version of the National Centers for Environmental Prediction (NCEP) atmospheric GCM [close to the 2001 version of the Medium-Range Forecast (MRF) model] coupled to a mixed layer ocean over the Atlantic. The mixed layer model consists of a 50-m slab ocean with "flux correction" similar to that in Peng et al. (2006) but without the Ekman transport, as detailed in appendix A. Although the atmosphere-ocean coupling is relatively simple, there is evidence from previous studies that thermodynamic coupling alone is useful for the seasonal prediction of Atlantic SST anomalies (e.g., Giannini et al. 2004; Saravanan and Chang 2004). In multiyear test runs with climatological SST imposed outside the Atlantic, climate drift in SST is found to be small within the coupled domain. In the hindcast experiment we will use the model-simulated SST minus the observed climatological SST to define the SST anomaly to be compared to observation. The domain for the mixed layer ocean model is from $50^{\circ} \mathrm{S}$ to $36^{\circ} \mathrm{N}$ over the Atlantic (as shown in Figs. 4-7). The entire South Atlantic is included because we are interested in the preconditioning in boreal winter in the South Atlantic (see Fig. 1c). Additional remarks on the detail of the mixed layer model are in appendix A.

Each hindcast run is a one year integration starting from a generic 1 September initial state for the atmosphere. An ensemble of 25 runs for each case is constructed by randomly perturbing the midtropospheric divergence field in the atmospheric initial condition. The atmospheric model is integrated for two months uncoupled and forced with climatological SST and then coupled to the mixed layer model on 1 November when an observed SST anomaly is imposed in the initial condition over the coupled domain. The coupled model is then integrated forward to August of year 1. For most cases, we will focus on the results from November of year 0 to June of year 1 . Because the observed Atlantic SSTs have only monthly (or weekly in selected recent times) resolution, the "initial state" of SST on 1 November used in our simulation is actually taken from the average of the monthly means of October and November of the selected year.

A prototypical outcome of a prediction run with a three-member ensemble shown, in Fig. 3, serves to illustrate the behavior of the coupled model. To construct a meaningful example, the SST anomaly in the initial state in the Atlantic on 1 November is constructed from the composite of seven cases (see figure caption) that have a large, positive SST anomaly over the South Atlantic box in Fig. 1c. Imposing the composite SST anomaly for the Atlantic in the initial condition, the three runs are performed with the climatological SST imposed outside the coupled domain. The simulated daily SST anomalies averaged over the South Atlantic box are shown in Fig. 3 with the individual ensemble members in color and the ensemble mean in black. Although the switch-on of coupling and the addition of the initial perturbation in the SST on 1 November is rather abrupt, Fig. 3 shows that, after a brief initial drop in amplitude, the model retained a substantial fraction of the initial perturbation and allowed it to persist into the boreal spring of year 1 . The filled and open circles show the monthly means of the simulated (ensemble mean) and observed (composite of the seven selected years) SST anomalies for the South Atlantic box from November to June. The SST anomaly drops off more quickly in the model than in the observation but the former still has an $e$-folding time longer than a season.

Three types of runs are performed for each of the selected cases described in section 2a. The "initial condition only" (IC-only) runs are similar to the example in Fig. 3 and are performed with the observed SST anomaly imposed in the initial (1 November) state but with the seasonally varying climatological SST imposed outside the coupling domain. The "ENSO forcing only" (ENSO-only) runs are without any initial SST perturbation on 1 November but with the observed SST anomaly over the tropical Pacific $\left(15^{\circ} \mathrm{S}-15^{\circ} \mathrm{N}, 165^{\circ} \mathrm{E}-90^{\circ} \mathrm{W}\right)$ added to the imposed climatological SST outside the coupling domain. The ENSO + IC runs have both ENSO forcing from the Pacific and the initial perturbation in the SST over the Atlantic. (For the ENSO-only and $\mathrm{ENSO}+\mathrm{IC}$ runs, during the first two months the ENSO forcing in the Pacific is already turned on.) Unless otherwise noted, each type of runs consists of a 25member ensemble of one year integration (i.e., a total of 75 runs for each of the ENSO events described in 


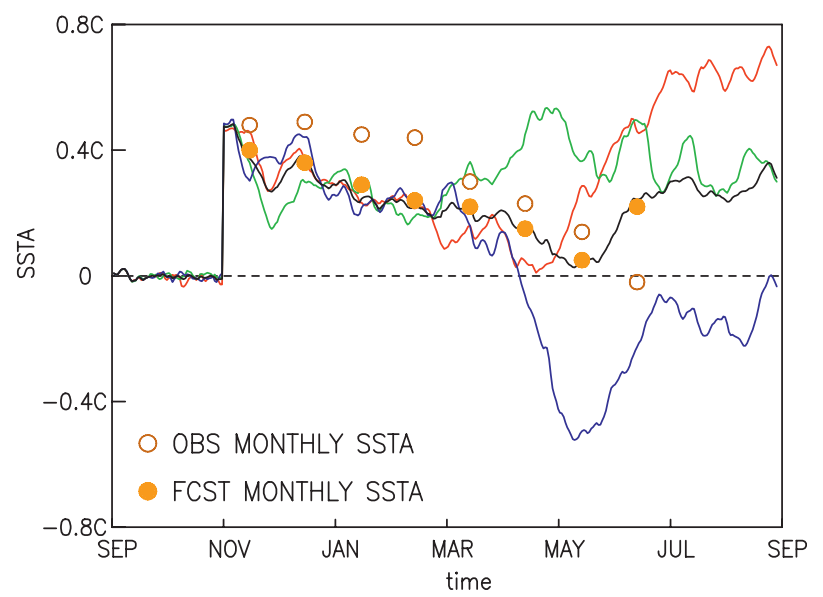

FIG. 3. A test run for illustrating the behavior of the hindcast model showing the simulated daily surface temperature anomalies averaged over the South Atlantic box in Fig. 1c for the ensemble mean (black) and the individual ensemble members (colored lines) for a set of 3-member runs. The initial SST perturbation, imposed on the mixed layer model at 1 Nov of year 0 (when the coupling is turned on), is constructed from the composite of the average of the October and November monthly SST anomalies from 1953, 1959, 1969, 1974, 1983, 1988, and 1994. The selected years satisfy the criterion that the SSTA of $(\mathrm{Oct}+\mathrm{Nov}) / 2$ averaged over the South Atlantic box is greater than $0.3^{\circ} \mathrm{C}$. The filled and open circles are the simulated (ensemble mean) and observed (composite of the six selected years) monthly SSTA for the South Atlantic box.

section 2a). In addition, a 25-member "control run" is performed with no ENSO forcing and no initial perturbation (but with coupling turned on) on 1 November. This set of runs will be used to define the simulated precipitation anomalies in section 4 . Table 1 summarizes the major hindcast runs performed for this study.

\section{Hindcast of SST}

\section{a. Hindcast of Atlantic SST}

Figures $4 \mathrm{a}$ and $4 \mathrm{~b}$ show the observed SST anomalies over the Atlantic in November 1968 and April 1969. Figures $4 \mathrm{c}-\mathrm{e}$ show the ensemble mean of the SST anomalies in April 1969 from the hindcast runs with IC only, IC+ENSO forcing, and ENSO forcing only. The shaded areas are with above $95 \%$ statistical significance, based on the signal-to-noise ratio estimated from the ensemble mean and the intraensemble standard deviation. In the observation, tSA is initially positive, while tNA is slightly negative in November 1968 . The gradient, $\mathrm{G} 1=\mathrm{tNA}-\mathrm{tSA}$, increases to a positive value in April 1969 owing to the warming in tNA-a canonical response to the positive ENSO forcing from boreal winter to spring (e.g., Huang et al. 2005a). This is captured by the hindcast runs with ENSO+IC (Fig. 4d) and
ENSO-only (Fig. 4e). In the IC-only runs (Fig. 4c), the SST anomaly in the South Atlantic in April retains the structure of the initial state in November. However, in North Atlantic, the initial SST anomaly in November decays to nearly zero in April. These results suggest that, in the model runs, tNA in boreal spring was controlled primarily by the ENSO forcing from boreal winter to spring, while tSA was influenced by the persistence of the preconditioning in the preceding winter.

Figure 5 is similar to Fig. 4 but for the 1970/71 case (Figs. 5b-e are for April 1971), an ENSO cold event in which tNA turned from nearly neutral in November to cold in April (Figs. 5a and 5b). The initially positive tropical Atlantic SST gradient is reversed to negative in spring. This is captured by the hindcast runs with ENSO+IC or ENSO-only, although the model simulations produced too cold SST anomalies over the equatorial Atlantic and tropical South Atlantic. In the IConly runs, the pattern of SST anomaly in the South Atlantic persisted while that in the tropical North Atlantic dissipated to nearly zero, a behavior similar to the 1968/69 case (Fig. 4c). In the ENSO only runs, the response in the tropical South Atlantic is very weak. Again, in this case, the simulated tNA is dominated by ENSO forcing while tSA is determined by the persistence of the preexisting anomaly in winter.

Figure 6 shows the observation and hindcast for the 1982/83 case (Figs. 6b-e are for April 1983), a strong ENSO warm event. In this case, the response in tNA is canonical; it turns from negative in November (Fig. 6a) to strongly positive in April (Fig. 6b). The close resemblance of Figs. 6d and 6e indicates that the response in spring in the ENSO+IC runs is dominated by the ENSO forcing. In the model, the SST response to ENSO forcing in the equatorial Atlantic and tropical South Atlantic is positive enough (Fig. 6e) to overwhelm a negative SST anomaly from the persistence of the initial condition as inferred from the IC-only runs (Fig. 6c), resulting in a net positive response in the ENSO + IC runs opposite to that observed. Nevertheless, the positive response in tNA is strong enough that the model still predicted a positive G1 in spring, qualitatively consistent with that observed. The errors in the simulated equatorial Atlantic SST could be related to the omission of ocean dynamics in the ocean model. In addition, the excessive warming over the tropical Atlantic in the ENSO+IC and ENSO only runs may also be attributed in part to the model bias in the atmospheric response to Pacific ENSO forcing. As discussed in appendix B, the model response in the tropical tropospheric temperature over the Atlantic sector is too strong (too warm during El Niño and too cold during La Niña) compared to observation. 


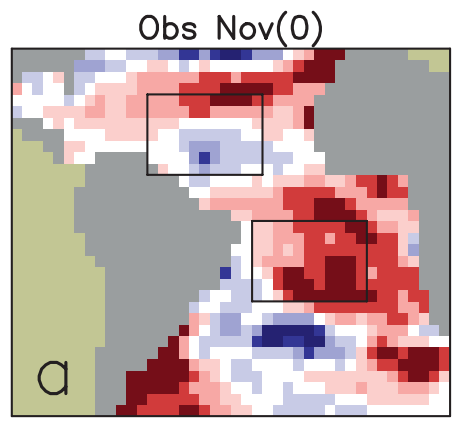

Hcst IC only

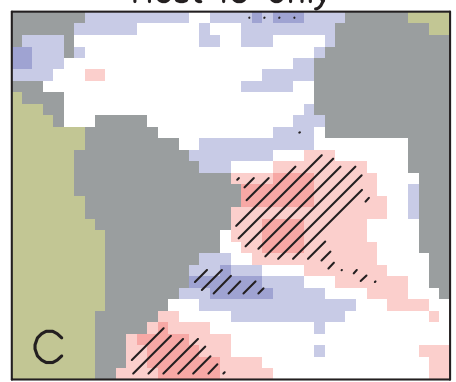

\section{Obs Apr(1)}

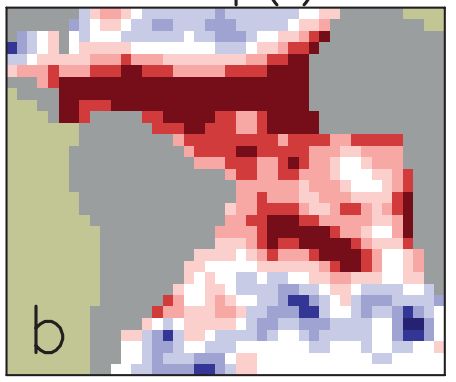

Hcst IC+ENSO

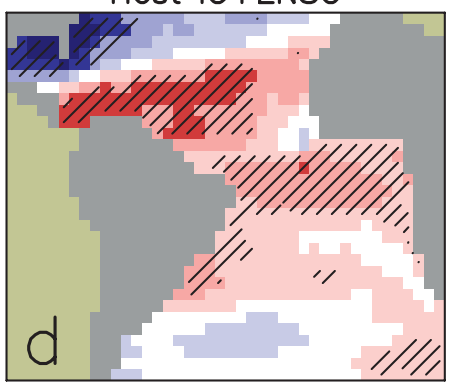

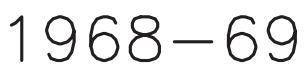

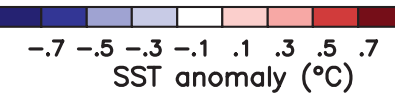

Hcst ENSO only

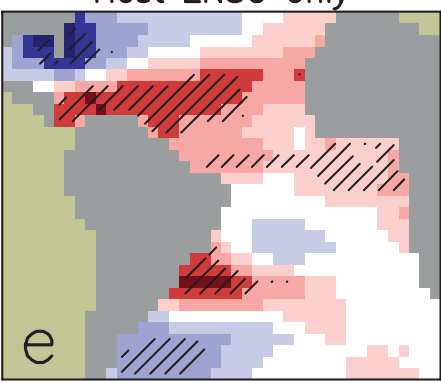

FIG. 4. SST anomalies for the $1968 / 69$ case: (a) observed SSTA in November of year 0 (1968), (b) observed SSTA in April of year 1 (1969). The 25-member ensemble means of the model-simulated SSTA with (c) IC-only, (d) EN$\mathrm{SO}+\mathrm{IC}$, and (e) ENSO-only (see text for detail). Shading indicates a high level $(>95 \%$, using the ensemble mean anomaly and intraensemble variance to define the signal-to-noise ratio) of statistical significance. The tNA and tSA boxes are marked in (a).

The results for the other three cases are shown in an abridged fashion in Fig. 7, with the left and middle columns the observed SST anomalies in November of year 0 and April of year 1, and the right column the simulated SST anomaly in April of year 1. The hindcasts in the right column are from the ENSO+IC runs except for 1993/94 (Fig. 7f), which is from the IC only runs. For the 1988/89 ENSO cold event, the ENSO+IC runs produced the cooling of tNA in spring, but not as pronounced as that observed. The simulated SST anomalies in the equatorial and tropical South Atlantic are too cold. This error also occurred in the ENSO-only runs but not in the IC-only runs (not shown), indicating that it is related to the aforementioned model bias in the atmospheric response to ENSO. The model still produced the correct sign (negative) of G1 in boreal spring owing to the simulated substantial cooling in tNA.

The 1993/94 case (middle row of Fig. 7) is unique in that it is an ENSO neutral year with a very strong preconditioning in the Atlantic. Moreover, the observed pattern of the SST anomaly persisted from November 1993 to April 1994 for almost the entire Atlantic domain, preserving the negative G1 from the initial state. The IC only hindcast runs correctly produced the cool tNA, warm tSA, and negative G1 in boreal spring. Since this is a neutral year, the ENSO+IC runs (not shown) produced similar results as the IC-only runs. With the correct prediction of the tropical Atlantic SST, in section 4 we will further demonstrate a useful prediction in the precipitation over South America from this case.

For the 1995/96 cold event (bottom row of Fig. 7), the ENSO + IC runs simulated the cooling trend from boreal winter to spring in tNA. The simulated cooling is somewhat excessive, culminating in a negative tNA in April 1996 opposite to that observed. The simulated SST anomalies in spring are also colder than observed for the equatorial Atlantic and tropical South Atlantic. This behavior also exists in the ENSO only runs (not shown). Yet, even in this case, the model correctly simulated the sign of G1 (negative) in spring as that observed.

A quick conclusion from the above six cases is that the sign of G1 in boreal spring is not difficult to reproduce in the model simulations. For the ENSO years, this is because the model correctly simulates the warming or cooling in tNA through the robust ENSO-tNA connection. The response in tNA is usually strong enough that, even with some errors in tSA and/or the equatorial Atlantic SST, the sign of G1 in the hindcast can still remain correct. However, the errors in tSA and equatorial Atlantic SST are not without a consequence. We will show in section 4 that they degrade the prediction of precipitation in some areas in South America. 


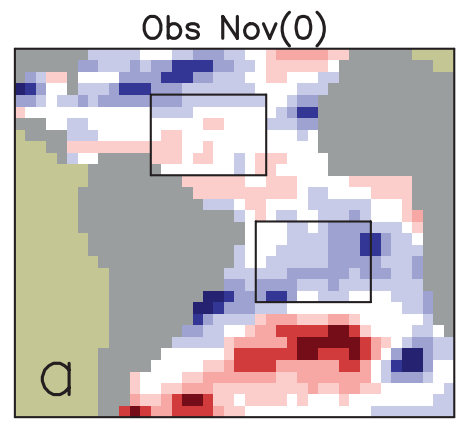

Hcst IC only

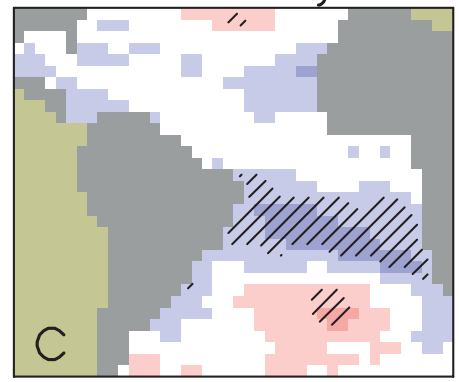

Obs Apr(1)

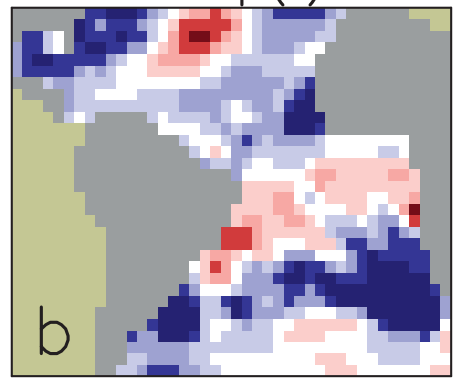

Hcst IC+ENSO

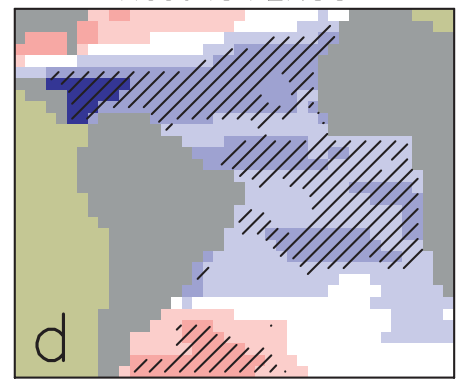

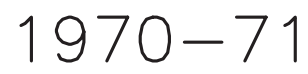

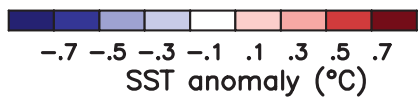

Hcst ENSO only

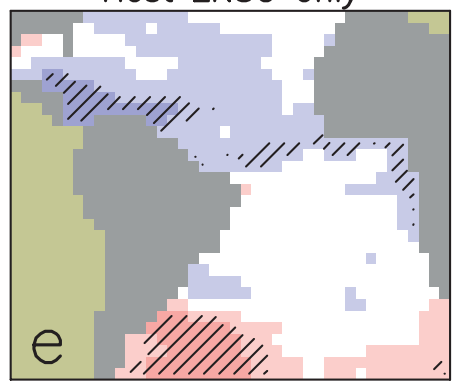

FIG. 5. As in Fig. 4 but for the 1970/71 case.

\section{b. The evolution of tropical Atlantic SST gradient}

The behavior of the monthly-mean Atlantic SST gradient, G1, is summarized in Fig. 8 for the (a) 1968/69, (b) 1970/71, and (c) 1993/94 cases. Black, blue, and red indicate the observation and the hindcast runs with
ENSO + IC and IC only, respectively. The half length of the vertical bar indicates one (intraensemble) standard deviation. For the 1968/69 warm event with an initially negative G1, without the ENSO forcing the negative G1 persisted into spring (the IC-only runs). The observed upward trend in G1 and the negative value of G1 in
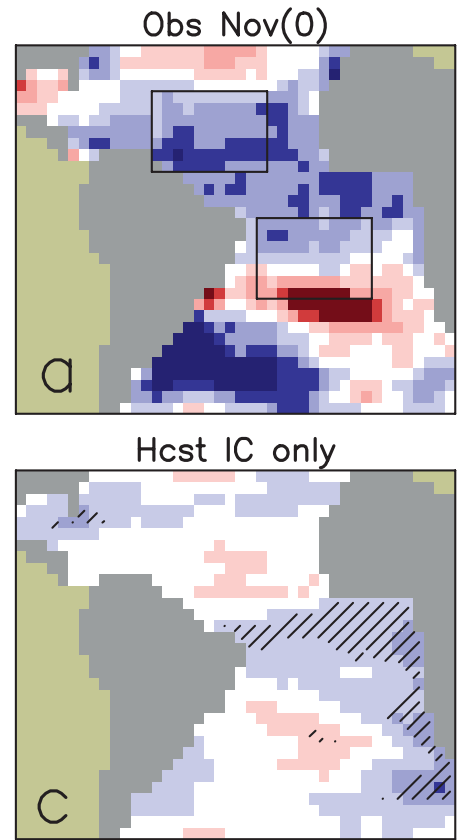
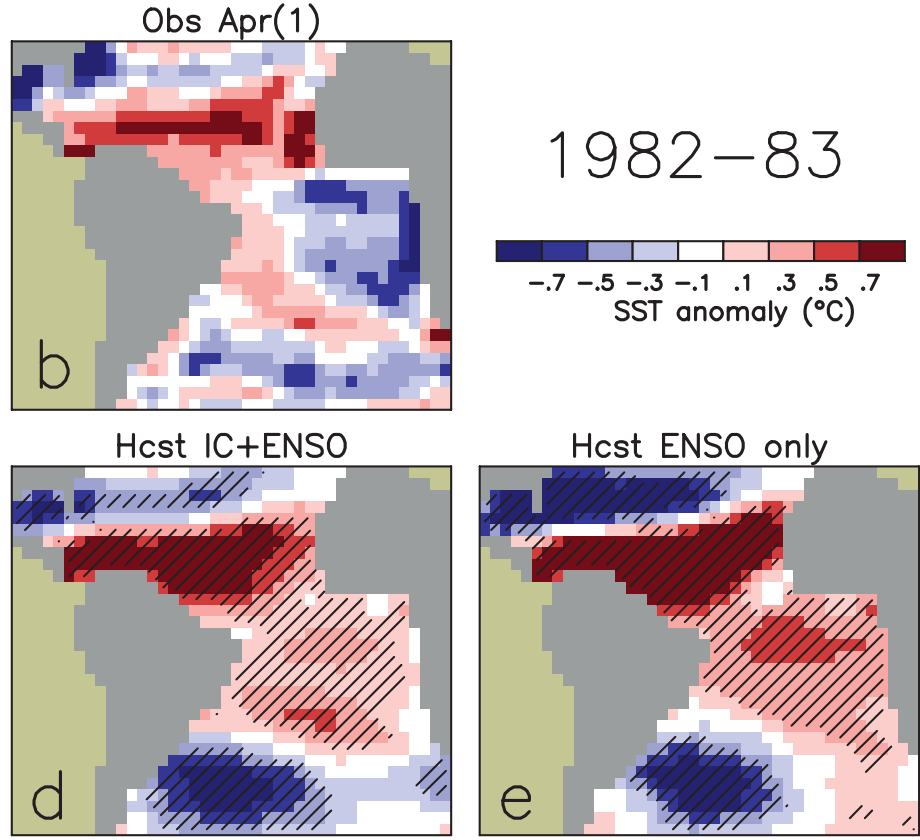

FIG. 6. As in Fig. 4 but for the 1982/83 case. 


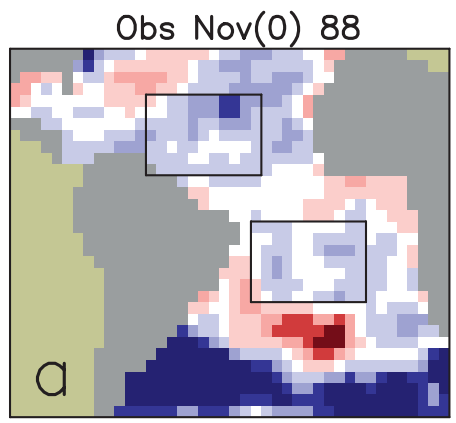

Obs $\operatorname{Nov}(0) 93$

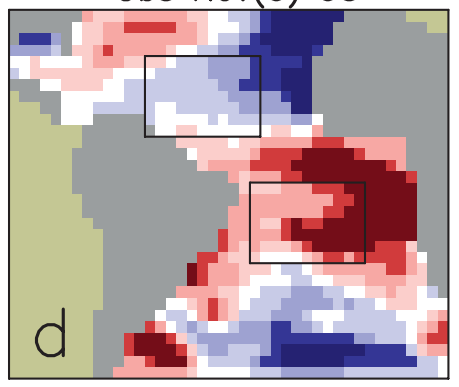

Obs $\operatorname{Nov}(0) 95$

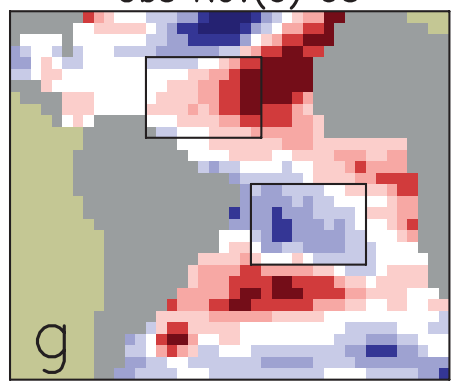

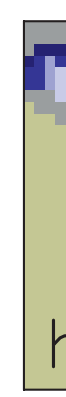
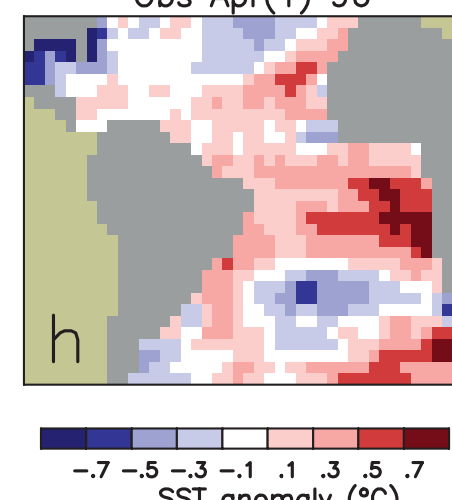
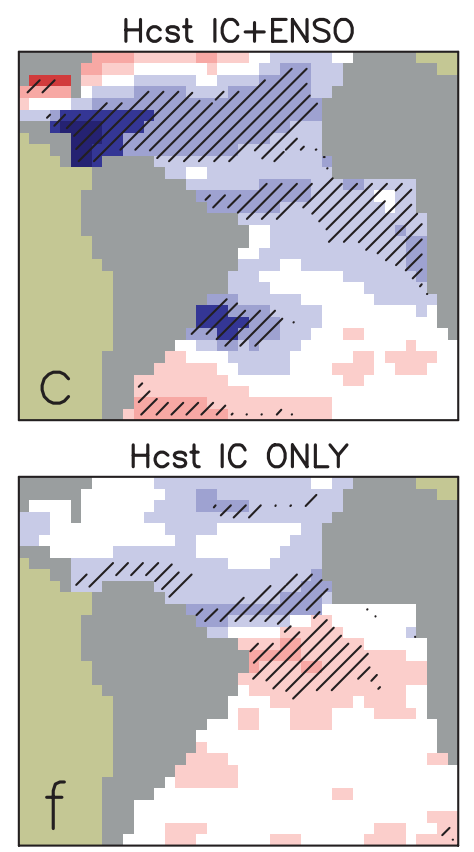

\section{Hcst IC+ENSO}

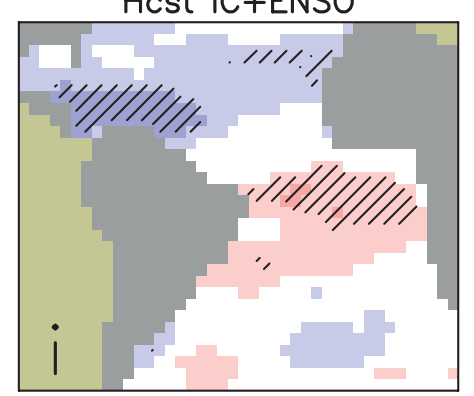

FIG. 7. Similar to Fig. 4 but for (top) 1988/89, (middle) 1993/94, and (bottom) 1995/96: (left column) observed SSTA in November of year 0; (middle column) observed SSTA in April of year 1; and (right column) simulated SSTA from the hindcast experiments. For the (c) 1988/89 and (i) 1995/96 cases the ENSO+IC runs are shown. For the 1993/94 case, an ENSO neutral year, the IC-only runs are shown in the right column.

spring are correctly simulated with the added ENSO forcing, which dominates in this case. The behavior of the 1970/71 case in Fig. 8 b is similar to that of the 1968/69 case but just with a reversal of sign for the SST anomalies; the IC-only runs simulated persistence of a positive G1 into spring, while the ENSO+IC runs correctly produced the downward trend in G1 and a negative G1 in spring, as observed. The behavior of G1 for other ENSO years discussed in section $3 \mathrm{a}$ is qualitatively similar to the above two. For those years, the inclusion of the ENSO forcing is essential for the prediction of G1 in spring.

An intriguing case in which ENSO forcing does not dominate is 1993/94, shown in Fig. 8c (also see Figs. 7d-f).
Since this is a neutral year, the "ENSO forcing" has only a minor contribution to the prediction of G1 (the difference between the ensemble means of the blue and red curves in Fig. 8c is not statistically significant at $95 \%$ level). In the observation (black), an initially strongly negative G1 persisted and maintained its amplitude into spring. The IC-only runs reproduced this persistence although with a greater decay of the amplitude of G1 with time than that observed. Even so, the predicted G1 in April remains strongly negative.

\section{c. Further remarks}

The results of the hindcast experiments may generally depend on the model and the manner of atmosphere- 

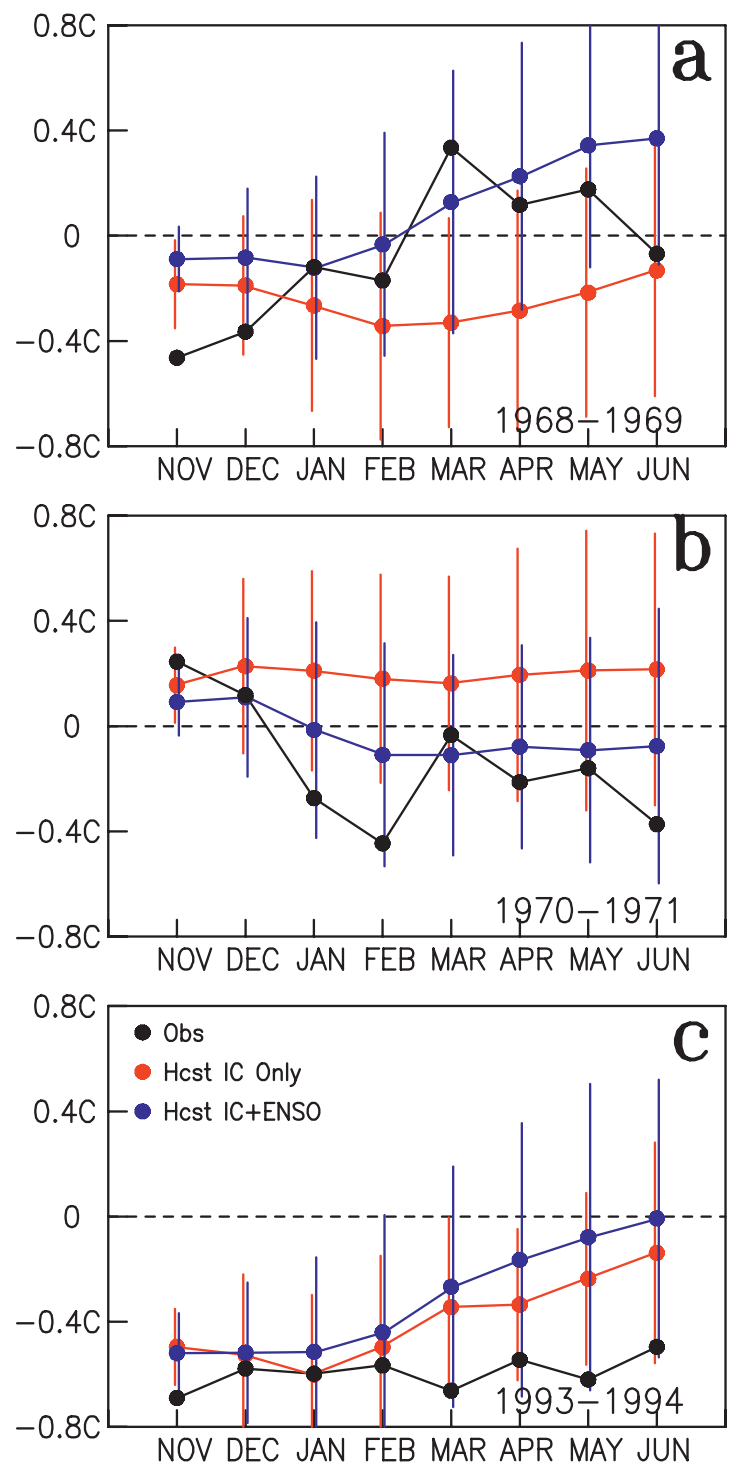

FIG. 8. Observed (black) and model-simulated (blue with ENSO+IC, red with IC-only) monthly-mean G1 for (a) 1968/69, (b) 1970/71, and (c) 1993/94.

ocean coupling. To quickly assess the behavior of our coupled model, we compare the ENSO-induced surface fluxes in our simulations to other studies. Figure 9 shows the effect of the ENSO forcing, defined as the difference between the ensemble means of the ENSO-only and control runs, on the surface energy fluxes for DecemberFebruary from ENSO "warm minus cold" composite (see caption for detail). A positive flux anomaly (red) indicates an energy flow into the ocean, corresponding to heating in the SST. The ENSO-induced anomalous latent heat flux (LHF, left) is strongly positive over tNA - the major cause for the warming there from winter to spring. This is consistent with previous studies (e.g.,
Alexander and Scott 2002). In the Northern Hemisphere, the anomalous longwave (LW, middle) and shortwave (SW, right) radiative fluxes as responses to ENSO forcing are generally weaker than the anomalous LHF. The LW and SW contributions tend to cancel each other. The SW and LW radiative fluxes in Fig. 9 are somewhat different from those in Alexander and Scott (2002, using a more sophisticated mixed layer model with vertical variations), in which the ENSO forcing induces a positive signal in SW and a moderately negative signal in LW over the tNA region and the Caribbean. In our simulation, the response in the sensible heat flux is weaker than in the other three components and is not shown. Figure 9 also shows that the ENSOinduced surface energy flux anomalies are generally stronger in the North than in the South Atlantic.

In previous studies (e.g., Czaja et al. 2002; Enfield et al. 2006; Lee et al. 2008; a review by Kushnir et al. 2006), the evolution of the tNA SST anomaly is sometimes discussed in connection with the North Atlantic Oscillation (NAO). These studies have focused on the longer time scales, for example, the interannual variability of NAO and tNA based on the seasonal mean NAO and tNA indices. Here we have not emphasized this connection (although the information of the phase of NAO is embedded in the initial condition for the tNA SST in our simulations) because we are concerned with the short-term, subseasonal evolution of tNA SST anomalies within a season. On this shorter time scale, the variability of NAO is not well understood, but it has been shown by recent studies to be largely a manifestation of synoptic weather events with a decaying time scale of less than 10 days (Feldstein 2000; Benedict et al. 2004). The evolution of the NAO index on the very short time scale can, then, be viewed as part of the synoptic noise in our seasonal forecast and needs not be discussed separately. (Moreover, in our hindcast experiment, this high-frequency noisy component is significantly reduced after averaging the 25 ensemble members.) On the interannual and longer time scale (as previous studies have investigated), a more structured air-sea interaction process involving NAO and Atlantic SST may emerge after the high-frequency noise is filtered out. Our problem of seasonal forecast lies between these two extremes, but the short-term influence of random synoptic events likely remains important. Thus, for our current discussion we choose not to further separate NAO from the general short-term, subseasonal noise.

In our analysis we have treated tNA and tSA as separate entities, noting that tNA is generally more strongly influenced by ENSO and tSA by internal variability. The role of the cross-equatorial interaction 

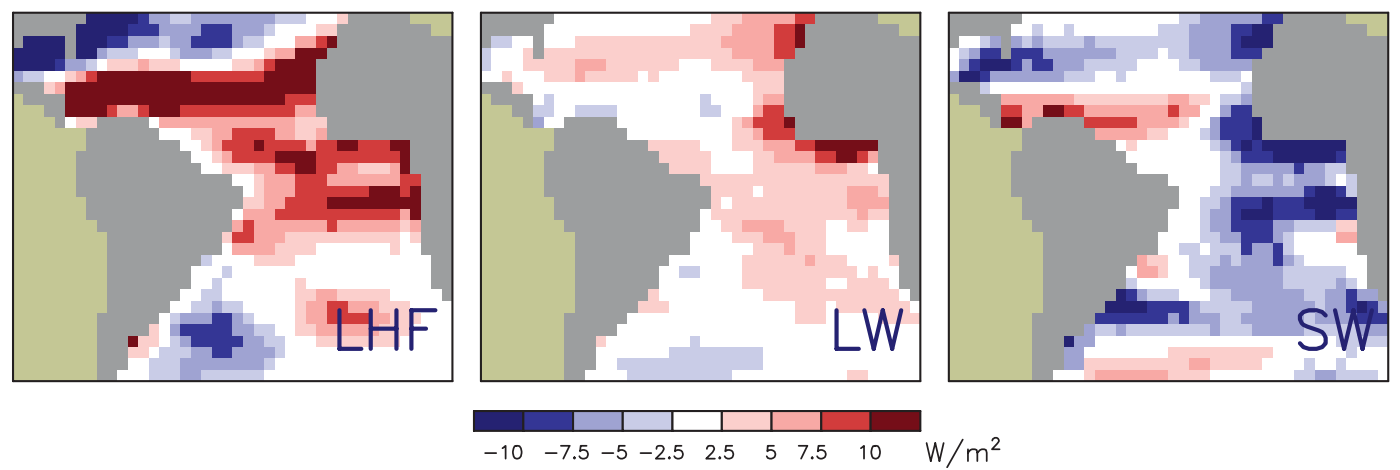

FIG. 9. The ENSO-induced anomalies in (left) surface latent heat flux, (middle) longwave radiative energy flux, (right) and shortwave radiative energy flux averaged from December of year 0 to February of year 1 and defined as the difference between the ensemble means of the ENSO-only and control runs. Shown is the ENSO warm minus cold composite, defined as the average of the two warm events $(1968 / 69,1982 / 83)$ minus the average of the three cold events $(1970 / 71,1988 / 89,1995 / 96)$. Red (positive) means a net energy flux into the ocean, corresponding to heating in the SST.

between tSA and tNA in enhancing the persistence [e.g., through wind-evaporation-SST (WES) feedback; Xie 1999] of both of them is an interesting possibility for further studies. The persistence of the SST anomalies may also depend on season-another point that can be further explored by applying our hindcast system to other seasons.

\section{Hindcast of precipitation}

Since our study of the Atlantic SST gradient is motivated by its potential influence on the precipitation over northern South America, we will next examine the simulated precipitation anomalies from the hindcast experiments. The interpretation of the simulated precipitation anomalies is complicated by the fact that the ENSO forcing not only indirectly influences South American rainfall by modifying the Atlantic SST gradient but it can also affect the precipitation through a more direct thermodynamical mechanism [e.g., Chiang and Sobel (2002); further interpretation in Huang et al. (2005b)]. Briefly, a plausible scenario of this direct influence is related to (consider an ENSO warm event) the eastward spreading of warm tropospheric air along the equator from the Pacific to the South American and Atlantic sector (Yulaeva and Wallace 1994; Chiang and Sobel 2002). The resultant warmer air aloft causes an increase in the static stability of the atmosphere over northern South America, thereby a suppression of rainfall there. Thus, northern South America is dry during El Niño and wet during La Niña. This mechanism exists in the ENSO+IC and ENSO-only hindcast runs and it is entangled with the effect of the Atlantic SST gradient in determining the precipitation anomalies over South America. Only in the IC-only runs can we clearly relate the precipitation anomalies to the Atlantic SST or SST gradient.

Unlike the SST over the coupled domain that is constrained by the flux correction, the model-predicted precipitation has a more noticeable bias over the tropical Atlantic and South America. The bias over this region is a common problem for GCMs (e.g., Biasutti et al. 2006). In boreal spring, our model produced excessive rainfall over the Amazon Basin compared to observations (not shown). To circumvent the problems arising from the precipitation bias, we define the predicted precipitation anomaly as the difference between the ensemble means of the 25 -member hindcast runs and that of another set of 25-member "control runs" (instead of the observed climatology) that retain the coupling over the Atlantic but not ENSO forcing nor imposed initial perturbations in the SST.

The observed precipitation anomalies to be used for model validation are constructed from the daily gridded South American precipitation dataset of Liebmann and Allured (2005). A quality check is performed to exclude the grid points where too few observations (too few days - usually 10 days as the threshold-per month) are available to robustly define the climatology and/or monthly-mean anomaly for a particular month. They are left blank in the panels for the observation shown in Figs. 10-13. We will discuss only the four most recent cases of our simulations in the post-1980 era, for which the observation of precipitation has the highest quality.

To assess the impacts of the error in the Atlantic SST on the simulated precipitation, we will further compare our results with a set of nine-member Atmospheric Model Intercomparison Project (AMIP) runs-atmospheric GCM forced by the observed SST - using a GCM similar to our hindcast model (both are the T42 28-level version 

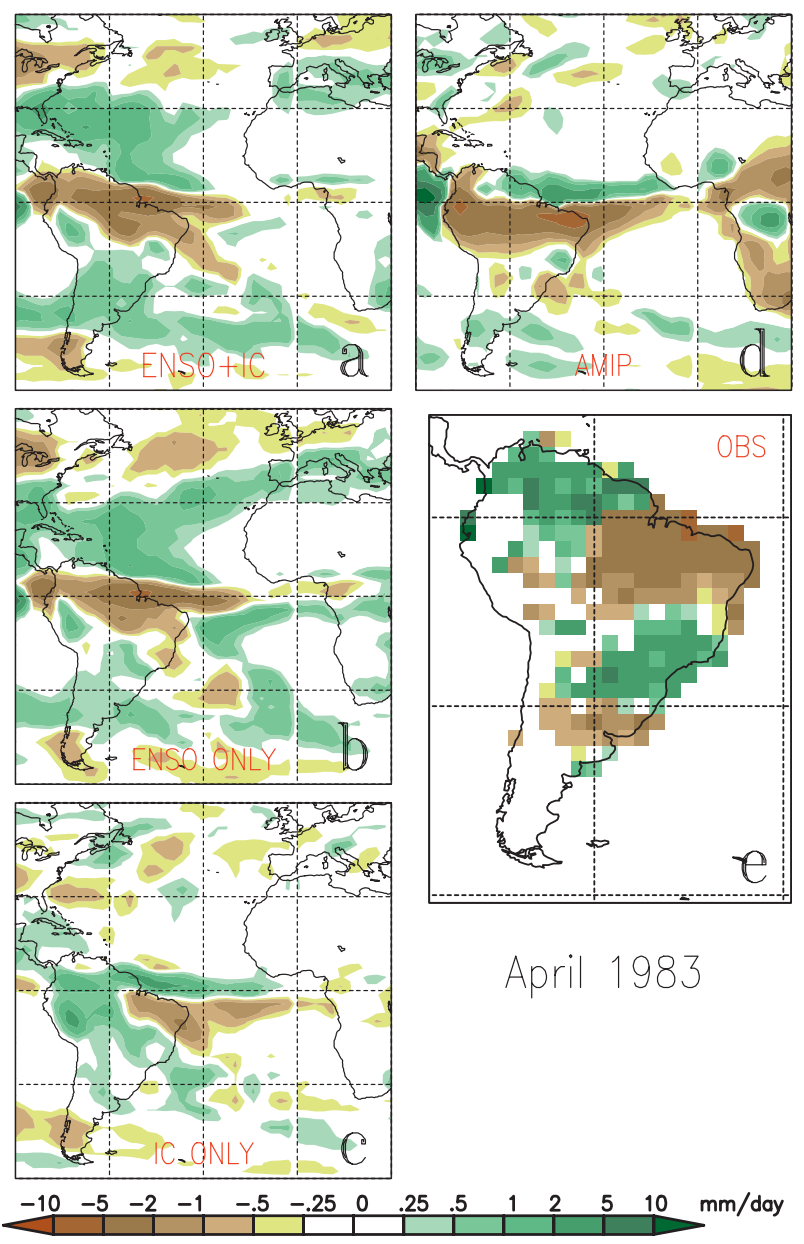

FIG. 10. Precipitation anomalies for April 1983: (a) hindcast with ENSO+IC, (b) hindcast with ENSO-only, (c) hindcast with IC-only, (d) AMIP runs, and (e) observation; Panels (a)-(c) are 25 -member ensemble means from the 1982/83 case and (d) the nine-member ensemble mean. Color scale is shown at bottom.

of the NCEP atmospheric GCM but the latter is a slightly more recent version). The model output for the AMIP runs is made available to us through the International Research Institute for Climate and Society (IRI) Data Library. For the AMIP runs, the precipitation anomalies are defined as the departure from the long-term mean deduced from the same set of simulations.

Figure 10 shows the precipitation anomalies for April 1983 from the 25-member ensemble means of our hindcast runs with (a) ENSO+IC, (b) ENSO-only, and (c) IC-only-all to be compared to (d) the 9-member ensemble mean of the AMIP runs-and (e) the observation. The ENSO+IC hindcast runs and the AMIP runs both reproduced the typical dryness over northern Brazil for this ENSO warm event. The observed wetness over northern (north of the equator) South America is partially reproduced by the AMIP runs but is absent in
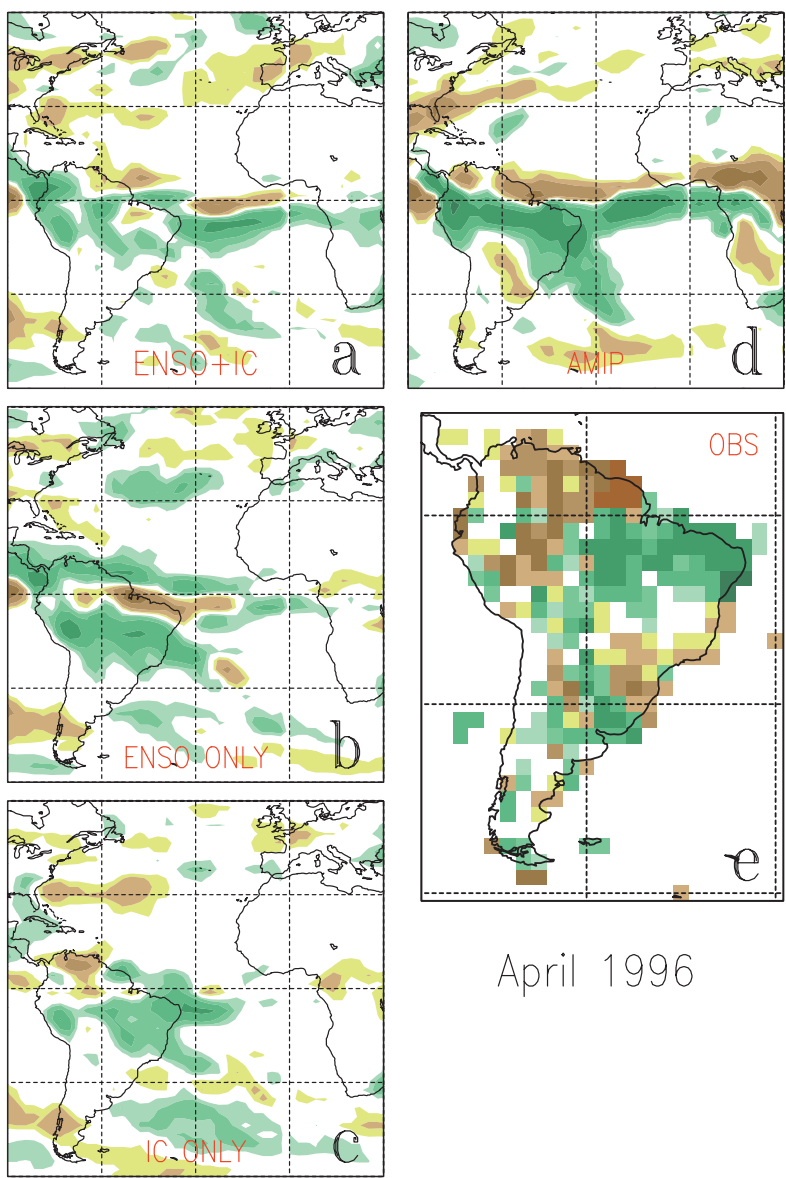

April 1996

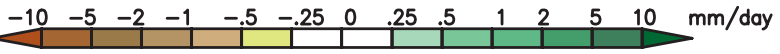

FIG. 11. As in Fig. 10 but for April 1996 (hindcast runs for the 1995/96 case): (a) ENSO+IC, (b) ENSO-only, (c) IC-only, (d) AMIP runs, and (e) observation.

the ENSO+IC runs, which also produced wetness farther north over the Caribbean. In the above comparison, it should also be noted that the observation in Fig. 10e represents just one realization, in contrast to the ensemble means in Figs. 10a and 10b. The disagreement in the small-scale structures between the model and observation may be due to sampling. For this strong El Niño case, the simulated drying over northern South America is mainly due to the ENSO forcing. The result of the ENSO-only runs (Fig. 10b) is similar to that of the ENSO+IC runs (Fig. 10a). The IC-only runs (Fig. 10c) produced, overall, a weaker response but, nevertheless, capture the drying over the Nordeste. The precipitation anomalies in Fig. 10c can be clearly related to the simulated Atlantic SST anomalies (Fig. 6c). The dipolelike structure (that straddles the equator) in the precipitation anomaly corresponds to a northward shift of the ITCZ, consistent with a cool tSA and positive G1 in Fig. 6c. Incidentally, the precipitation anomalies over 

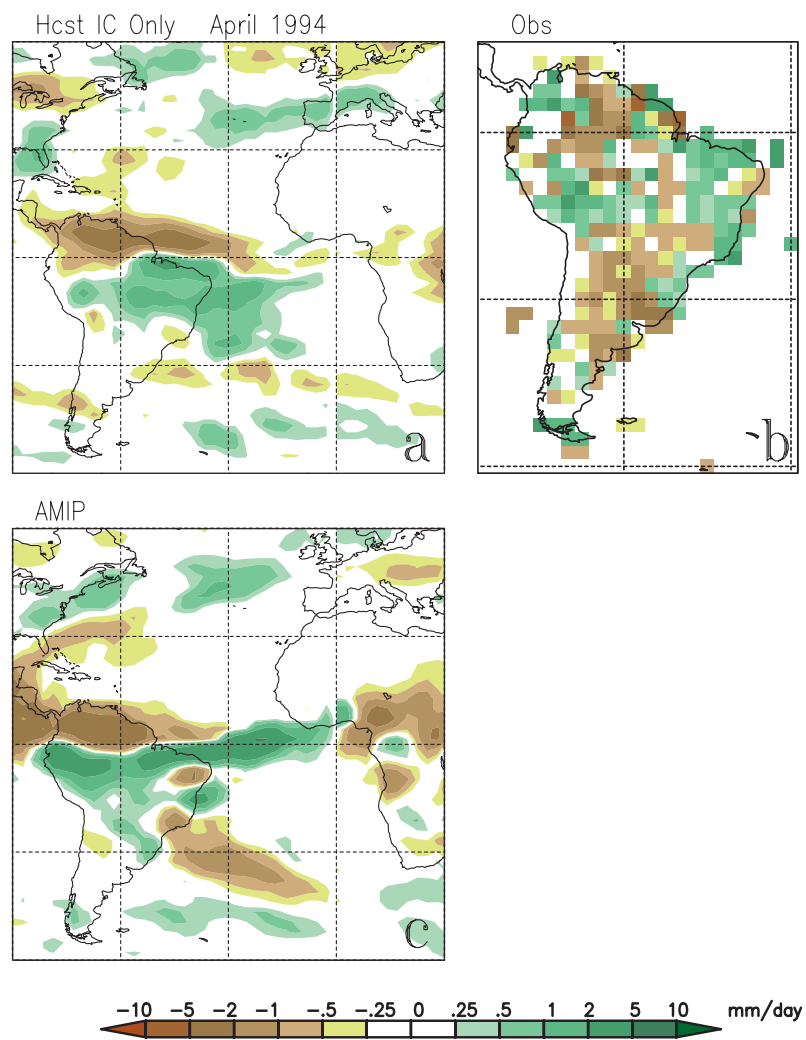

FIG. 12. Precipitation anomalies for April 1994: (a) hindcast with IC-only, (b) observation, and (c) AMIP runs.

the equatorial Atlantic and the northern tip of South America from the IC-only runs are more consistent with the observation (and AMIP runs) than those from the $\mathrm{ENSO}+\mathrm{IC}$ or ENSO only runs. The latter two produced excessive drying centered on the equator (versus south of the equator in the IC-only runs, AMIP runs, and observation). This is related to the excessive tropical tropospheric warming as the model bias in the response to El Niño (appendix B). The effect of the bias somewhat diminished the benefit of adding the ENSO forcing to the hindcast runs even though the forcing was shown to help the prediction of tNA. A similar concern about the mixed benefit of the ENSO forcing for the prediction of remote precipitation anomalies in a coupled model was also put forth by Misra and Zhang (2007).

Figure 11 is similar to Fig. 10 but for April 1996 from the 1995/96 case, a cold event. Except for a reversal of sign, the behavior of the observed and simulated precipitation anomalies in this case is similar to that in Fig. 10. The typical wetness over northern Brazil associated with a cold event is observed (Fig. 11e) and simulated by the AMIP runs (Fig. 11d). The wetness is also simulated by the full hindcast (ENSO+IC) runs (Fig. 11a) but it is weaker compared to Figs. 11d and 11e. The IC-only runs
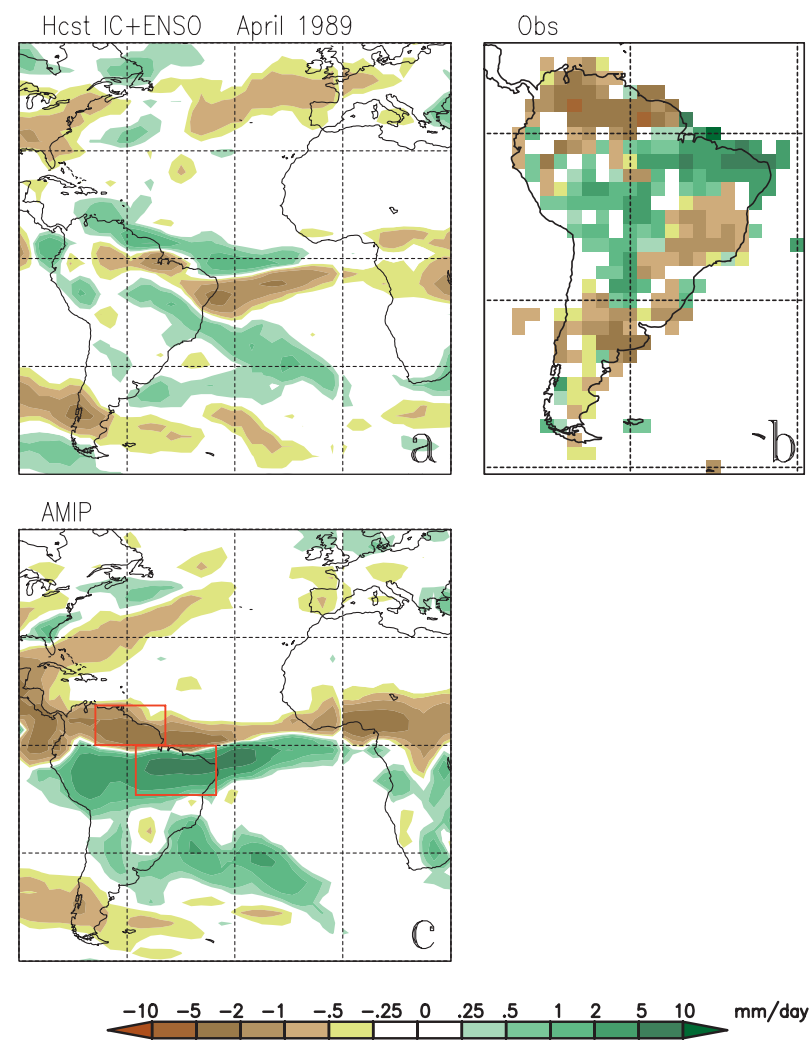

FIG. 13. As in Fig. 12 but for April 1989 (hindcast runs for the $1988 / 89$ case). In (c), the red boxes north and south of the equator over South America indicate the pNSA and pSSA regions, respectively, used for Fig. 14.

(Fig. 11c) also produced wetness over northern Brazil and a hint of dryness over the northern tip of South America similar to that observed. The result from the ENSO only runs (Fig. 11b) is mixed. Except for a smallscale dry stripe located along the north shore of northern Brazil, the hindcast produced large-scale wetness over most of northern South America. While this is qualitatively a typical response to La Niña, the simulated wetness was too widespread; for example, the northern tip of South America is wet, opposite to that observed. This may, again, be related to the bias in the model response to ENSO forcing. Figures 11a-c also demonstrate that linear superposition cannot be applied to the simulated precipitation field. The sum of the outcomes of the ENSO-only and IC-only runs does not equal that of the ENSO+IC runs owing to the nonlinear dependence of precipitation on the SST and atmospheric circulation.

Figure 12 is similar to Fig. 11 but for the neutral year of 1993/94 (shown is April 1994), and only the IC-only hindcast runs are shown in Fig. 12a. The hindcast with only the information of the initial SST anomaly in November 1993 produced realistic features in the precipitation anomaly with wetness over northern Brazil and 
dryness over the northwestern tip of South America, similar to that observed (Fig. 12b) and simulated by the AMIP runs (Fig. 12c). The wetness over northern Brazil and dryness north of it in Fig. 12a can be clearly related to the cool tNA and warm tSA (and negative G1) in the simulated SST anomalies (Fig. 7f) that also agree with the observations (Fig. 7e).

Figure 13 is similar to Fig. 12 but for the ENSO cold event of 1988/89 (shown is April 1989), a case in which the full ENSO+IC hindcast runs (Fig. 13a) performed poorly in reproducing the observed precipitation anomaly (Fig. 13b) over South America. The AMIP runs (Fig. $13 \mathrm{c}$ ), on the other hand, reproduced the observed wetness over northern Brazil and dryness over the northwestern tip of South America. As discussed in section $3 \mathrm{a}$, for this event, although the ENSO forcing in the $\mathrm{ENSO}+\mathrm{IC}$ runs produced the observed cooling trend in tNA and the correct sign of G1, it also produced excessive and unrealistic cooling in tSA and the equatorial Atlantic - the sign of the SST anomalies there is opposite that observed. In this case, the negative impact of the latter is substantial enough to render the simulated precipitation anomalies inaccurate over the aforementioned regions in South America.

Figure 14 shows the root-mean-square error in the model-simulated precipitation anomaly for April of year 1 over northern tropical South America (pNSA, top panel) and southern tropical South America (pSSA, bottom panel) regions as indicated by the red boxes in Fig. 13c. The error is calculated from the difference between the ensemble mean of the model simulation and the observation (interpolated onto model grid) at every grid point over land within the box and is evaluated for the AMIP, ENSO+IC, ENSO-only, and IC-only runs. From left to right are the three individual ENSO cases, their average, and the neutral case of 1994. The error over pSSA is generally smaller than that over pNSA. For all ENSO cases, except pNSA in 1983, the ENSO + IC runs outperform the ENSO-only runs in predicting the precipitation anomalies in April. This indicates useful predictability of South American rainfall embedded in the Atlantic preconditioning.

As a summary, except for the 1988/89 case, we found that the relatively simple AGCM + mixed layer (ML) coupled model qualitatively reproduced the observed dryness or wetness over northern Brazil south of the equator. For the ENSO years, a greater discrepancy in the precipitation anomalies between the hindcast runs with ENSO forcing and the observation or AMIP runs occur over northern (north of the equator) and equatorial South America and equatorial Atlantic. This error is attributed in part to the model bias in the atmospheric response to Pacific ENSO forcing (appendix B). Note

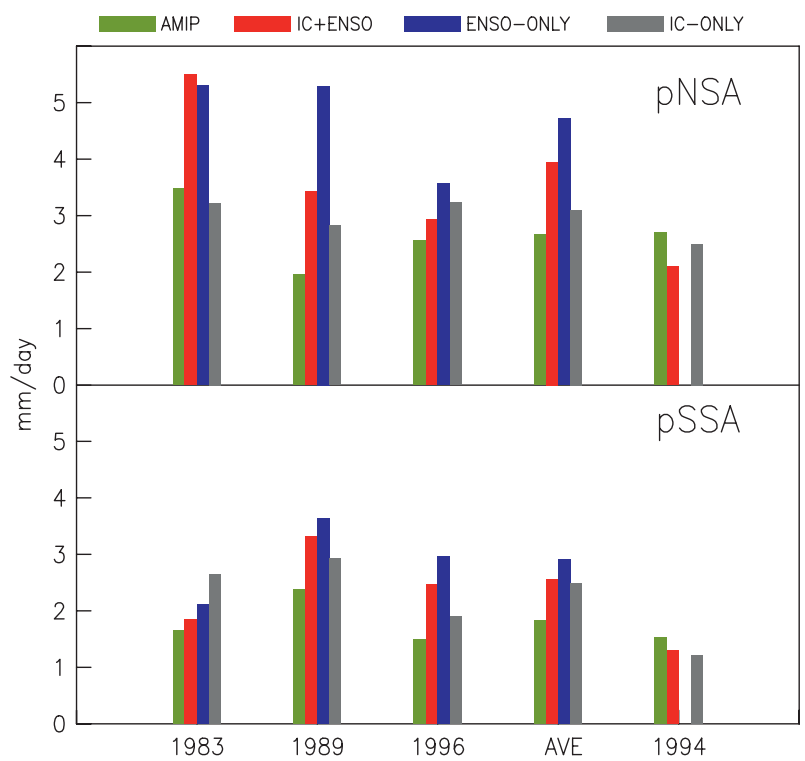

FIG. 14. Rms error in the precipitation anomaly for April of year 1 averaged over (top) the pNSA and (bottom) the pSSA regions as defined in Fig. 13c. The error is calculated from the rms of the ensemble mean of the hindcast minus observation at every grid point over land within the box. The errors associated with the AMIP, ENSO+IC, ENSO-only, and IC-only runs are shown in green, red, blue, and gray. The three groups of bars at left are for the three individual post-1980 ENSO events discussed in the text. The group marked by "AVE" is the average over the three events. The error for the neutral year 1994 is shown at right.

that this negative impact of the ENSO forcing on the hindcast of South American precipitation does not contradict the positive impact discussed in section 3 on the correct simulations of the Atlantic SST gradient, G1. As explained before, for ENSO years the success of the latter is mainly due to the ability of the model to simulate tNA through the ENSO-tNA connection. Our results here imply that the precipitation anomalies over the equatorial South America and equatorial Atlantic depend on more than just tNA and/or the sign of G1. Interestingly, the hindcast for the 1993/94 case does not suffer the problem of the biased response to ENSO since it is a neutral year with minimal ENSO forcing. It reproduced both the observed wetness over northern Brazil and the dryness north of it. Moreover, devoid of the imposed ENSO forcing, the successful IC-only "hindcast" may be regarded as a "forecast" since in this simulation the predictability of the South American precipitation anomalies in April 1994 is embedded in the initial condition of the SST in November 1993.

\section{Concluding remarks}

Our analyses of the hindcast experiments indicate that, in the cases with a persistent ENSO forcing from 
boreal winter to spring, the forcing is the dominant factor in determining the evolution of the tropical Atlantic SST gradient, G1, and the sign of G1 in late spring. In the absence of ENSO forcing, the sign of G1 in boreal winter tends to persist into spring such that the preconditioning in the Atlantic SST also provides a nonnegligible contribution to the overall value of $\mathrm{G} 1$ in spring. This finding confirms the results of previous observational analyses of a primary role of ENSO but a nonnegligible secondary role of Atlantic preconditioning in determining $\mathrm{G} 1$ in boreal spring for ENSO eventsrecall the statistics of two-thirds concordant versus onethird discordant in Huang et al. (2005a). In most cases our hindcast runs with ENSO+IC correctly simulated the sign of G1 in late spring. For the ENSO years, this success is mainly due to the correct simulation of tNA due to its clear connection to ENSO forcing.

The majority of our hindcast runs also simulated reasonable precipitation anomalies over northern Brazil south of the equator, although for ENSO years a larger discrepancy is found between the simulated and observed precipitation anomalies over northern and equatorial South America and equatorial Atlantic. This is attributed in part to the model bias in the atmospheric response to ENSO forcing. For the ENSO events, the ENSO+IC runs generally outperform the ENSO-only runs in predicting the rainfall anomalies over the northern half of South America, indicating predictability of South American rainfall embedded in the Atlantic preconditioning. While there is still room for improvement for our model given its biased response to ENSO forcing, the results of this study at least demonstrated that a correct simulation of tNA and the sign of G1 alone does not sufficiently lead to an accurate simulation of the rainfall anomalies over equatorial South America and northern South America. The improved simulations for these regions by the AMIP runs indicate that accurate information in tSA and the equatorial Atlantic SST is needed for the prediction of the precipitation anomalies in boreal spring in these regions in South America.

The most interesting case of our numerical experiments is the hindcast (essentially "forecast") for the neutral year of 1993/94, for which the IC-only runs using the observed SST anomaly in November 1993 produced realistic tropical Atlantic SST gradient and precipitation anomalies over northern South America in April 1994. The relationship between the simulated Atlantic SST gradient and South American rainfall anomalies, namely, a negative G1 accompanying the wetness over northern Brazil and the dryness north of it, is consistent with the canonical picture derived from previous observational analyses. The 1993/94 case presents an intriguing example of useful seasonal forecast of G1 and South American rainfall anomalies without ENSO.

Acknowledgments. The authors thank Dr. Brant Liebmann for providing the South American precipitation dataset used in this study. The comments and suggestions from three anonymous reviewers helped improve the manuscript. This work was supported by NSF Grant ATM-05-43256, NOAA CLIVAR-Atlantic Program, NOAA CPPA Program, and the CICAR Award NA03OAR4320179 from NOAA, U.S. Department of Commerce.

\section{APPENDIX A}

\section{Tests for the AGCM+ML Model}

The mixed layer model consists of a 50-m slab ocean with flux correction. The formula for flux correction follows Peng et al. (2006) but excludes the Ekman transport effect because our desired coupling domain includes the equator [in its vicinity the formula for Ekman transport in Peng et al. (2006) becomes singular]). As detailed in Peng et al., the daily climatology of the SST, $T_{\mathrm{C}}$, was first constructed from the observation. It was used to force a 60-member ensemble of atmospheric GCM simulations to produce the daily climatology of the (downward) surface heat flux, $Q_{\mathrm{C}}$. The prognostic equation for the SST in the mixed layer model can be written in terms of the anomalies of the SST $(T)$ and heat flux $(Q)$ :

$$
\frac{\partial T^{\prime}}{\partial t}=\frac{Q^{\prime}}{\left(\rho c_{p} H\right)}
$$

where $T^{\prime}=T-T_{\mathrm{C}}$ and $Q^{\prime}=Q-Q_{\mathrm{C}}$ are the departure from daily climatology, $c_{p}$ is the heat capacity of seawater, and $H=50 \mathrm{~m}$ is the depth of the mixed layer. In the coupled model, after (A1) is used to renew $T^{\prime}$, the total SST is used to force the AGCM. The model is integrated forward to produce the new $Q^{\prime}$, and so on. In this study, we have used a constant $H=50 \mathrm{~m}$ for the whole Atlantic Ocean, although the model has the option of adopting a more realistic spatially varying $H$ (e.g., the mixed layer depth off the west coast of Africa is generally shallower than $50 \mathrm{~m}$ ) in future experiments.

With the constraint of flux correction, the simulated SST does not drift significantly from the climatological seasonal cycle. Figure A1 shows an example of the SST averaged over the South Atlantic box shown in Fig. 1c from a 5-yr test run. Black and red are the observed climatology (repeated for $5 \mathrm{yr}$ ) and the model-simulated 


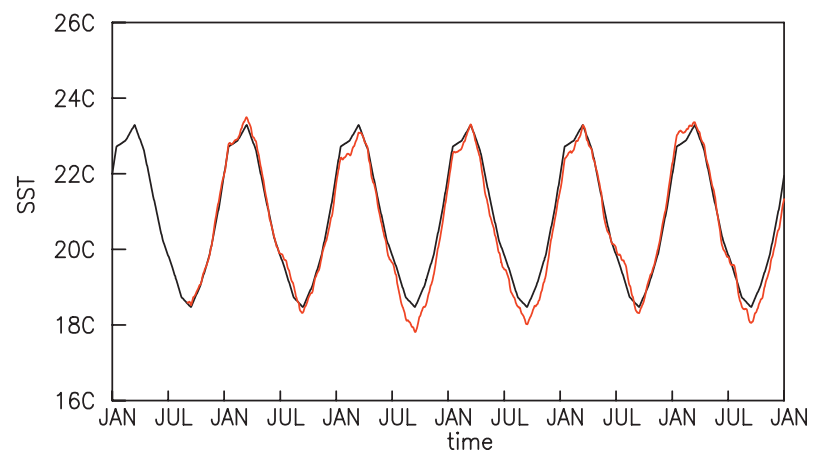

FIG. A1. SST averaged over the South Atlantic box in Fig. 1c from observation (black, with repeated seasonal cycle) and a 5-yr test run of the AGCM+ML model (red).

SST. The behavior of the simulated SST over other regions, for example, the tNA and tSA boxes in Fig. 1a, is similar to that shown in Fig. A1. The climate drift in the SST is generally small during the first 10 months, the duration of our coupled hindcast runs.

We have also performed another set of sensitivity test by extending the northern boundary of the mixed layer model from $36^{\circ}$ to $50^{\circ} \mathrm{N}$ for the $1968 / 69$ case. The behavior of simulated tNA, tSA, and G1 in boreal spring remain very similar to those from the unmodified case discussed in the main text.

\section{APPENDIX B}

\section{Atmospheric Response to ENSO Forcing in the AGCM+ML Model}

As noted in sections 3 and 4 , the errors in the hindcast of Atlantic SST may be attributed in part to the model bias related to the atmospheric response to Pacific ENSO forcing. While a comprehensive diagnosis of the model bias is beyond the scope of this study, we will use the 1982/83 case to illustrate an aspect of this bias and its implications for the simulated Atlantic SST. We choose to examine this particular year because it has the strongest Pacific ENSO forcing. Moreover, since the five ENSO warm and cold events that we studied each has its own distinctive life cycle (with their maximum SST anomalies peaking at different times), a composite of the five events might not necessarily lead to a clearer picture of the bias.

Figure B1a shows the atmospheric response to the Pacific ENSO forcing in the vertically averaged temperature from our model simulations. The ENSO response is defined as the 25 -member ensemble mean of the ENSO only runs for 1982/83 minus the 25-member ensemble mean of the control runs (forced by climato-
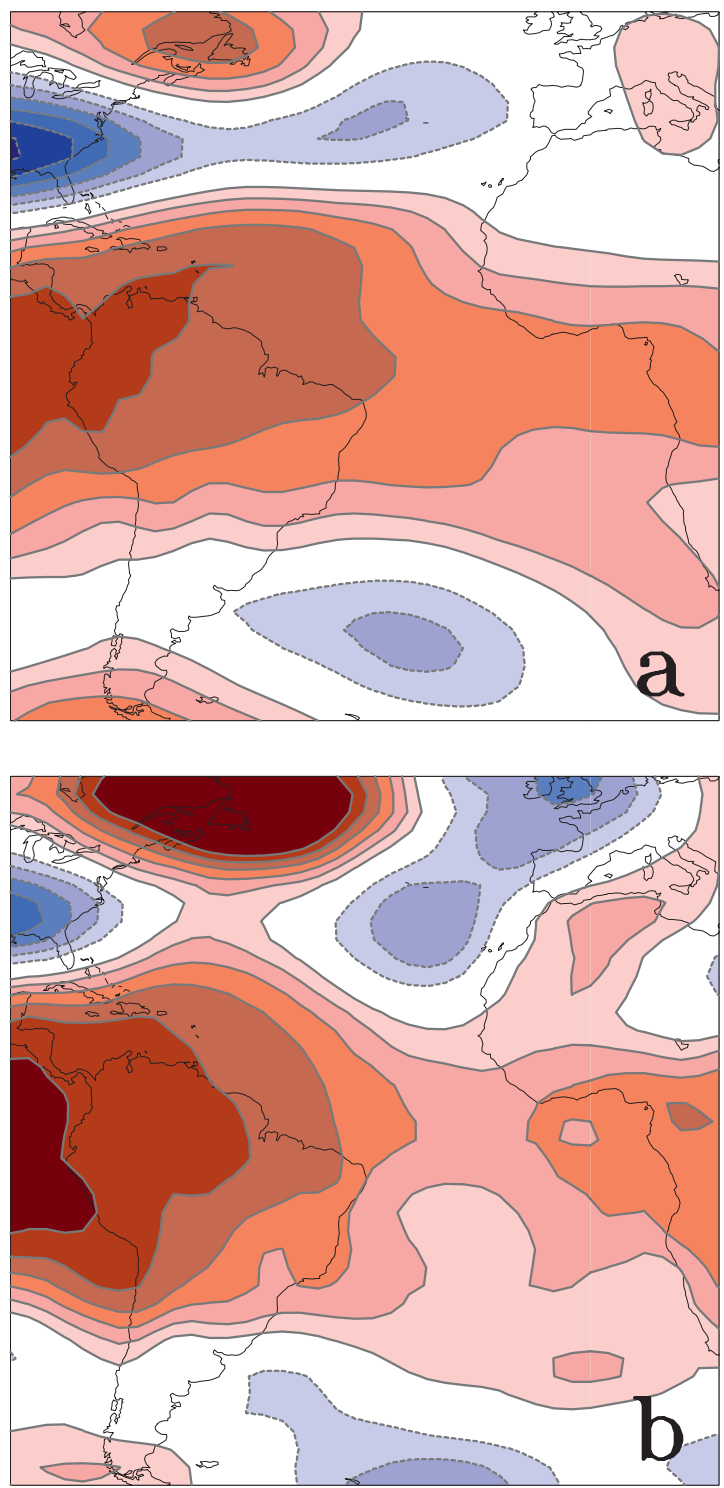

FIG. B1. (a) Model-simulated response to the tropical Pacific ENSO forcing in the vertically averaged temperature, defined as the mass-weighted average of temperature from the surface to $\sigma \approx 0.1$, where $\sigma$ is the terrain-following "sigma" coordinate. Shown is the temperature anomaly averaged from January to May 1983. (b) The observational counterpart of (a), constructed from sigmalevel temperature data from NCEP reanalysis. Contour interval is $0.2^{\circ} \mathrm{C}$. Red and blue are positive and negative, respectively. Areas with the absolute value of the temperature anomaly less than $0.2^{\circ} \mathrm{C}$ are not colored.

logical SST); both retain the coupling to the mixed layer model over the Atlantic. The temperature anomaly shown is the average from January to May 1983 and is the mass-weighted vertical average from the surface to $\sigma \approx 0.1$, where $\sigma=p / p_{s}$ is the terrain-following "sigma" coordinate. Figure B1b is the observational counterpart of B1a, using the sigma-level (spectral coefficient) data 
from NCEP reanalysis (Kalnay et al. 1996) and with the anomaly defined as the departure from the 1979-2003 climatology. As is well known, the atmospheric response to a Pacific ENSO SST anomaly generally consists of two components of quasi-stationary wave trains (e.g., Horel and Wallace 1981; Trenberth et al. 1998) and a zonally symmetric response (e.g., Chiang and Sobel 2002; Robinson 2002; Seager et al. 2003). The latter is especially prominent in the tropospheric temperature field, with zonal bands of tropical warming and extratropical cooling accompanying El Niño and the opposite accompanying La Niña (Yulaeva and Wallace 1994; Seager et al. 2003; Chiang and Sobel 2002). In Fig. $\mathrm{B} 1$, the zonally symmetric response in the tropospheric temperature is stronger in our simulation than that observed. In the former, the tropical tropospheric warmth spreads eastward more deeply into the Atlantic sector. In the observation, although there is still a positive temperature response on the equator, the temperature anomaly is more confined to the west of the Atlantic sector, with the maximum of the temperature anomaly partially blocked by the South American continent. (An examination of the 1995/96 ENSO cold event revealed a similar behavior-namely, in the model the ENSOinduced cold equatorial tropospheric temperature anomaly spreads farther into the Atlantic sector than that observed, causing a cold bias over the equatorial Atlantic, not shown.) Although many factors could potentially contribute to this bias, a plausible one is that the Andes mountain range is severely flattened in the model (due to its relatively coarse T42 resolution), allowing a more thorough eastward intrusion of the tropical tropospheric warm air into the Atlantic sector. The bias discussed here may contribute to the errors in the SST over the equatorial Atlantic and in the precipitation over equatorial South America and the equatorial Atlantic in our hindcast runs with ENSO forcing.

The effect related to the Andes is but one of the plausible explanations for the bias in tropical tropospheric temperature, shown in Fig. B1. For example, using the framework of Gill (1980) for the linear response of the tropical atmosphere to an ENSO-like SST forcing, it is known that the ratio of the amplitude of the zonally symmetric to zonally asymmetric temperature response increases with a decreasing damping coefficient (e.g., Gill 1980; Wu et al. 2001; Bretherton and Sobel 2003). The bias of an excessive zonally symmetric warmth induced by El Niño (coolness induced by La Niña) might also arise from too weak effective damping (by parameterized boundary layer friction, cumulus friction, etc.) in the tropics in our model. These possibilities are worth exploring in future work.

\section{REFERENCES}

Alexander, M., and J. Scott, 2002: The influence of ENSO on airsea interaction in the Atlantic. Geophys. Res. Lett., 29, 1701, doi:10.1029/2001GL014347.

Barreiro, M., A. Giannini, P. Chang, and R. Saravanan, 2004: On the role of the Southern Hemisphere atmospheric circulation in tropical Atlantic variability. Earth's Climate: The OceanAtmosphere Interaction, Geophys. Monogr. Ser., Vol. 147, Amer. Geophys. Union, 143-156.

_, P. Chang, L. Ji, R. Saravanan, and A. Giannini, 2005: Dynamical elements of predicting boreal spring tropical Atlantic sea surface temperatures. Dyn. Atmos. Oceans, 39, 61-85.

Benedict, J. J., S. Lee, and S. B. Feldstein, 2004: Synoptic view of the North Atlantic Oscillation. J. Atmos. Sci., 61, 121-144.

Biasutti, M., A. H. Sobel, and Y. Kushnir, 2006: AGCM precipitation biases in the tropical Atlantic. J. Climate, 19, 935-958.

Bretherton, C. S., and A. H. Sobel, 2003: The Gill model and the weak temperature gradient approximation. J. Atmos. Sci., 60, 451-460.

Chang, P., L. Ji, H. Li, C. Penland, and L. Matrosova, 1998: Prediction of tropical Atlantic sea surface temperature. Geophys. Res. Lett., 25, 1193-1196.

Chiang, J. C. H., and A. H. Sobel, 2002: Tropical tropospheric temperature variations caused by ENSO and their influence on the remote tropical climate. J. Climate, 15, 2616-2631.

Czaja, A., P. van der Vaart, and J. Marshall, 2002: A diagnostic study of the role of remote forcing in tropical Atlantic variability. J. Climate, 15, 3280-3290.

Enfield, D. B., and D. A. Mayer, 1997: Tropical Atlantic sea surface temperature variability and its relation to El NiñoSouthern Oscillation. J. Geophys. Res., 102, 929-945.

— S.-K. Lee, and C. Wang, 2006: How are large Western Hemisphere warm pools formed? Prog. Oceanogr., 70, 346-365.

Feldstein, S. B., 2000: The timescale, power spectra, and climate noise properties of teleconnection patterns. J. Climate, 13, 4430-4440.

Giannini, A., R. Saravanan, and P. Chang, 2004: The preconditioning role of tropical Atlantic variability in the development of the ENSO teleconnection: Implications for the prediction of Nordeste rainfall. Climate Dyn., 22, 839-855.

Gill, A. E., 1980: Some simple solutions for heat-induced tropical circulation. Quart. J. Roy. Meteor. Soc., 106, 447-462.

Horel, J. D., and J. M. Wallace, 1981: Planetary-scale atmospheric phenomena associated with the Southern Oscillation. Mon. Wea. Rev., 109, 813-829.

Huang, H.-P., A. W. Robertson, and Y. Kushnir, 2005a: Atlantic SST gradient and the influence of ENSO. Geophys. Res. Lett., 32, L20706, doi:10.1029/2005GL023944.

_ R. Seager, and Y. Kushnir, 2005b: The 1976/77 transition in precipitation over the Americas and the influence of tropical sea surface temperature. Climate Dyn., 24, 721-740.

Kalnay, E., and Coauthors, 1996: The NCEP/NCAR 40-Year Reanalysis Project. Bull. Amer. Meteor. Soc., 77, 437-471.

Kushnir, Y., W. A. Robinson, P. Chang, and A. W. Robertson, 2006: The physical basis for predicting Atlantic sector seasonalto-interannual climate variability. J. Climate, 19, 5949-5970.

Lee, S.-K., D. B. Enfield, and C. Wang, 2008: Why do some El Niños have no impact on tropical North Atlantic SST? Geophys. Res. Lett., 35, L16705, doi:10.1029/2008GL034734.

Liebmann, B., and D. Allured, 2005: Daily precipitation grids for South America. Bull. Amer. Meteor. Soc., 86, 1567-1570.

Misra, V., and Y. Zhang, 2007: The fidelity of NCEP CFS seasonal hindcasts over Nordeste. Mon. Wea. Rev., 135, 618-627. 
Nobre, C. A., and L. C. B. Molion, 1988: The climatology of droughts and drought prediction. The Impact of Climate Variations on Agriculture: Assessments in Semi-Arid Regions, M. Parry, T. R. Carter, and N. T. Konjin, Eds., Kluwer Academic, 305-323.

Peng, S., W. A. Robinson, S. Li, and M. A. Alexander, 2006: Effects of Ekman transport on the NAO response to a tropical Atlantic SST anomaly. J. Climate, 19, 4803-4818.

Robinson, W. A., 2002: On the midlatitude thermal response to tropical warmth. Geophys. Res. Lett., 29, 1190, doi:10.1029/ 2001 GL014158.

Saravanan, R., and P. Chang, 2004: Thermodynamic coupling and predictability of tropical sea surface temperature. Earth's Climate: The Ocean-Atmosphere Interaction, Geophys. Monogr., Vol. 147, Amer. Geophys. Union, 171-180.

Sardeshmukh, P. D., G. P. Compo, and C. Penland, 2000: Changes of probability associated with El Niño. J. Climate, 13, 4268-4286.

Seager, R., N. Harnik, Y. Kushnir, W. Robinson, and J. Miller, 2003: Mechanisms of hemispherically symmetric climate variability. J. Climate, 16, 2960-2978.
Trenberth, K. E., G. W. Branstator, D. Karoly, A. Kumar, N.-C. Lau, and C. Ropelewski, 1998: Progress during TOGA in understanding and modeling global teleconnections associated with tropical sea surface temperature. J. Geophys. Res., 103, 14 291-14 324.

Trzaska, S., A. W. Robertson, J. D. Farrara, and C. R. Mechoso, 2007: South Atlantic variability arising from air-sea coupling: Local mechanisms and tropical-subtropical interactions. J. Climate, 20, 3345-3365.

Uvo, C. B., C. A. Repelli, S. E. Zebiak, and Y. Kushnir, 1998: The relationship between tropical Pacific and Atlantic SST and northeast Brazil monthly precipitation. J. Climate, 11, $551-562$.

Wu, Z., E. S. Sarachik, and D. S. Battisti, 2001: Thermally driven tropical circulations under Rayleigh friction and Newtonian cooling. J. Atmos. Sci., 58, 724-741.

Xie, S.-P., 1999: A dynamic ocean-atmosphere model of the tropical Atlantic decadal variability. J. Climate, 12, 64-70.

Yulaeva, E., and J. M. Wallace, 1994: The signature of ENSO in global temperature and precipitation fields derived from the microwave sounding unit. J. Climate, 7, 1719-1736. 